\title{
Effect of Water Stress on Reproduction and Colonization of Podosphaera aphanis of Strawberry
}

\author{
Franca G. Rossi, ${ }^{1, \dagger}$ Belachew Asalf, ${ }^{1}$ Chloe Grieu, ${ }^{1}$ Rodrigo B. Onofre, ${ }^{2}$ Natalia A. Peres, ${ }^{2}$ David M. Gadoury, ${ }^{3}$ and Arne Stensvand ${ }^{1,4}$ \\ ${ }^{1}$ Division of Biotechnology and Plant Health, Norwegian Institute of Bioeconomy Research, 1431 Ås, Norway \\ ${ }^{2}$ Department of Plant Pathology, University of Florida, Gulf Coast Research and Education Center, Wimauma, FL 33598, U.S.A. \\ ${ }^{3}$ Plant Pathology and Plant-Microbe Biology Section, Cornell University, New York State Agricultural Experiment Station, Ge- \\ neva, NY 14456, U.S.A. \\ ${ }^{4}$ Department of Plant Sciences, Norwegian University of Life Sciences, 1433 Ås, Norway
}

\begin{abstract}
In a number of pathosystems involving the powdery mildews (Erysiphales), plant stress is associated with decreased disease susceptibility and is detrimental to pathogen growth and reproduction. However, in strawberry, anecdotal observations associate severe powdery mildew (Podosphaera aphanis) with water stress. In a 2017 survey of 42 strawberry growers in Norway and California, 40 growers agreed with a statement that water-stressed strawberry plants were more susceptible to powdery mildew compared with nonstressed plants. In repeated in vitro and in vivo experiments, we found that water stress was consistently and significantly unfavorable to conidial germination, infection, and increases in disease severity. Deleterious effects on the

$50 \%$ was correlated $\left(R^{2}=0.897\right)$ with germinability of conidia harvested from extant colonies that developed on plants growing at different levels of water stress. These studies confirm that $P$. aphanis fits the norm for biotrophic powdery mildews and hosts under stress. Mild water stress, compared with a state of optimal hydration, is likely to decrease rather than increase susceptibility of strawberry to $P$. aphanis. We believe it is possible that foliar symptoms of leaf curling due to diffuse and inconspicuous infection of the lower leaf surfaces by $P$. aphanis could easily be mistakenly attributed to water stress, which we observed as having a nearly identical leaf curling symptom in strawberry.
\end{abstract} pathogen were observed from both preinoculation and postinoculation water stress in the host. Soil moisture content in the range from 0 to
Keywords: abiotic stress, powdery mildew, small fruits
Powdery mildew, caused by Podosphaera aphanis, can be a devastating disease of strawberry (Fragaria $\times$ ananassa). The pathogen infects all aboveground organs and results in malformed or aborted fruit (Daubeny 1961; Peres and Mertely 2009). Conidia of $P$. aphanis are dispersed by wind (Blanco et al. 2004; Strand 2008), and germination is most favorable when temperatures are between 15 and $25^{\circ} \mathrm{C}$ (Amsalem et al. 2006; Peries 1962) and humidity is above $75 \%$ (Jhooty and McKeen 1965). Germination and colony development, however, are inhibited by free water, particularly when supplied as rain or overhead irrigation (Peries 1962).

Abiotic stresses, including extreme temperatures and water stress, generally reduce host suitability for biotrophic plant pathogens, in particular powdery mildews (Gadoury and Pearson 1988; Moyer et al. 2010; Weldon et al. 2017). The effect of water stress on P. apha$n i s$ has not been thoroughly investigated. However, substantial research on water stress and powdery mildews of other crops has been reported. Water-stressed barley (Ayres and Woolacott 1980; Wiese et al. 2004), cereals (Bencze et al. 2008), garlic mustard (Enright and Cipollini 2011), grapevine (Austin and Wilcox 2011), pepper (Caesar and Clerk 1985a, b), and tomato (Achuo et al. 2006) are less susceptible to powdery mildew compared with wellwatered plants. Water stress has been found to have an adverse

Current address for F. G. Rossi: Department of Global Plant Health, Driscoll's, Watsonville, CA 95076, U.S.A.

${ }^{\dagger}$ Corresponding author: F. G. Rossi; franca.rossi@driscolls.com

Funding: This work was supported by The Research Council of Norway through the SMARTCROP project (project number 244526).

The author(s) declare no conflict of interest.

Accepted for publication 30 April 2020.

C 2020 The American Phytopathological Society impact on the development and vigor of various powdery mildews. The length and width of conidia of Leveillula taurica on pepper plants decreased with decreased relative water content in the leaves, as did conidiophore length (Caesar and Clerk 1985b). Similarly, germination and appressorium formation by Blumeria graminis $\mathrm{f}$. $\mathrm{sp}$. hordei were inhibited in barley grown in dry soil, and the rate of colony expansion was reduced compared with plants grown in wet soil (Ayres and Woolacott 1980). In severely water-stressed garlic mustard (Alliaria petiolata), the colony size of Erysiphe cruciferarum was one-fifth that of well-watered plants (Enright and Cipollini 2011). Increased thickness of epidermal cell walls induced by water stress was negatively correlated with colony size in powdery mildew of barley (Ayres and Woolacott 1980). Water stress resulted in a twofold increase in foliar levels of abscisic acid and an increased resistance to Oidium neolycopersici on tomato (Achuo et al. 2006).

Despite the foregoing, we encountered a widespread belief among strawberry producers that severity of powdery mildew is causally related to water stress. In a 2017 survey of 42 strawberry growers in California and Norway, 40 agreed with a statement that waterstressed strawberries were more susceptible to powdery mildew than nonstressed plants. Our goal in the present study was to reconcile the foregoing perception among strawberry growers and reveal whether or not powdery mildew is a disease enhanced by water stress. Based on experimental evidence spanning a diversity of powdery mildews on other crops indicating decreased susceptibility to infection and decreased severity of disease due to water stress, we hypothesize that water stress will reduce the colonization and reproduction of the obligate biotroph powdery mildew in strawberry, just as water stress is debilitating to the plant. Our objectives were (i) to determine the degree to which timing and duration of water stress affected the incidence and severity of $P$. aphanis, and (ii) to assess the effect of water stress on germination of $P$. aphanis conidia.

\section{Materials and Methods}

Plant production. Strawberry plug plants of cultivar Korona were obtained from a certified nursery. Plants were potted in $11-\mathrm{cm}-$ diameter plastic pots containing a standard limed fertilized peat 
medium (Proff Go'Jord from Degernes Torvstrøfabrikk, Degernes, Norway). The growth medium contained 80 and $10 \%$ peat moss (Sphagnum spp.) classified as $\mathrm{H} 1$ to $\mathrm{H} 4$ and $\mathrm{H} 4$ to H6, respectively, on the von Post scale of humification and 10\% fine sand. Potted plants were contained and monitored for 2 weeks before transfer to the greenhouse to ensure that the plants did not have virusvectoring insects. During quarantine, plants were kept at a minimum air temperature of $20^{\circ} \mathrm{C}, 16$-h daylight period, and $80 \%$ relative humidity $(\mathrm{RH})$. All watering during quarantine and later for the experiments was done with fertilized water with an electric conductivity of $1.7 \mathrm{mS} / \mathrm{cm}$, with a mixture from stock solutions of Superba Rød (7-4$22 \mathrm{NPK}+$ micronutrients) and Calcinit $(15.5 \% \mathrm{~N}, 19 \% \mathrm{Ca})$.

Inoculum preparation. Emergent powdery mildew-free and ontogenically susceptible strawberry trifoliate leaves (approximately one-half mature size, phenological stages 3 to 4 sensu Asalf et al. 2014) were used for the maintenance and multiplication of $P$. aphanis for experiments on pathogen growth. Absence of powdery mildew prior to inoculation was confirmed by examining the leaves using a stereomicroscope at 10 to $30 \times$ magnification. Trifoliate leaves were surface sanitized in $0.5 \%$ sodium hypochlorite for $5 \mathrm{~min}$, rinsed twice in distilled water for $2 \mathrm{~min}$, and then air dried for 3 min under a laminar flow hood. The petiole was removed, and the leaves were divided into single leaflets, unfolded gently, and placed within 9-cm-diameter Petri dishes containing $0.5 \%$ water agar amended with $0.03 \%$ benzimidazole with the abaxial surface of the leaflets facing upward. The abaxial surface of the leaflets was then inoculated with conidia of $P$. aphanis, by touching them with leaves bearing 8- to 10-day-old sporulating colonies obtained from donor plants maintained as a source of inoculum. Each Petri dish contained four leaflets selected from four different leaves. Inoculated leaflets were then incubated in a growth chamber $\left(20^{\circ} \mathrm{C}, 16-\mathrm{h}\right.$ light/8-h dark photoperiod, and $80 \% \mathrm{RH}$ ). To maintain a source of inoculum, colonies were transferred to new sanitized leaflets every 8 to 10 days.

Severity of powdery mildew on leaves subjected to water stress in vivo. Following the 2 -week quarantine, 60 mildew-free cultivar Korona plants were transferred to the greenhouse $\left(18\right.$ to $20^{\circ} \mathrm{C}, 16$ h daylight period, $80 \% \mathrm{RH}$ ). A 15 -cm-diameter tray was placed beneath each plant, which was potted into an $11-\mathrm{cm}$-diameter plastic pot containing the growth medium previously described. Approximately $45 \mathrm{ml}$ of fertilized water (previously specified) was added daily to the tray for 3 weeks. The daily amount of water needed was determined by calculating average water lost by transpiration. Prior to the experiment, 20 cultivar Korona plants were used to calculate the average water lost by transpiration. Initially, the weight of the potted plants at soil water-holding capacity, which was measured by adding $100 \mathrm{ml}$ of water to the pot and then allowing the excess water to drain before weighing the pot, was subtracted from the weight after $24 \mathrm{~h}$. Enough water was added to account for the weight loss. After sufficient water was added, the potted plants were weighed again and then weighed once more after $24 \mathrm{~h}$. The process was repeated for 1 week.

After 3 weeks in the greenhouse, the plants were then divided into two groups of 30 plants each. One group continued to be watered as above, whereas the other was water stressed. Water stress was attained using a watering regime adapted from Enright and Cipollini (2011). Water-stressed plants were observed daily and deprived of water until wilting occurred. Plants were then supplied with approximately $45 \mathrm{ml}$ of water and allowed to wilt again. Two weeks later, following approximately four cycles of wilting in the waterstressed plants, leaves of both treatment groups were inoculated. One to two leaves per plant were tagged at either of two developmental stages: (i) stage 2, leaves light green, leaflets separated, lamina unfolded 15 to 30 degrees, and blades not reflexed from the petiole; and (ii) stage 3, leaves light green, leaflets separated, lamina unfolded more than 60 degrees, and blades reflexed from the petiole (Asalf et al. 2014). Leaves were inoculated with conidia harvested from 8- to 10-day-old sporulating colonies maintained on colonized leaves in Petri dishes and transferred to the adaxial and abaxial leaf surfaces using a fine artist's paintbrush. The tip of the brush was touched to the sporulating colony and then very lightly touched to and pulled across the adaxial and abaxial surfaces of the leaf to be inoculated. Following inoculation, plants were divided into the following treatment groups: (i) well-watered pre- and postinoculation (WW), (ii) water stressed pre- and postinoculation (SS), (iii) well-watered preinoculation and water stressed postinoculation (WS), and (iv) water stressed preinoculation and well-watered postinoculation (SW). Water stress postinoculation was attained as previously described. Each treatment group had five replicates of three strawberry plants each, and the experiment was organized in a randomized block design. The experiment was repeated twice with a 3-day interval between the inoculations.

Both latency period and severity of leaf colonization were assessed. The duration of the latency period was expressed as the

Table 1. Changes in soil moisture levels between days 1 and 21 postinoculation under four watering regimes: well-watered pre- and postinoculation (WW), water stressed preinoculation and well-watered postinoculation (SW), water stressed pre- and postinoculation (SS), and well-watered preinoculation and water stressed postinoculation (WS)

\begin{tabular}{lrrrrrrr}
\hline & \multicolumn{7}{c}{ Soil moisture (\%) } \\
\cline { 2 - 7 } Treatment & \multicolumn{1}{c}{ Day 1 } & \multicolumn{1}{c}{ Day 3 } & Day 7 & Day 10 & Day 12 & Day 15 & Day 21 \\
\hline WW & $39.7(5.2) \mathrm{a}^{\mathrm{z}}$ & $32.2(3.5) \mathrm{a}$ & $37.7(2.3) \mathrm{a}$ & $37.8(3.8) \mathrm{a}$ & $30.2(2.2) \mathrm{a}$ & $39.2(4.0) \mathrm{a}$ & $39.7(6.0) \mathrm{a}$ \\
SW & $10.7(1.6) \mathrm{b}$ & $38.2(2.3) \mathrm{a}$ & $36.6(2.8) \mathrm{a}$ & $37.9(3.5) \mathrm{a}$ & $35.4(3.4) \mathrm{a}$ & $39.5(1.2) \mathrm{a}$ & $41.0(4.2) \mathrm{a}$ \\
SS & $9.4(1.6) \mathrm{b}$ & $9.8(1.2) \mathrm{b}$ & $12.5(1.4) \mathrm{b}$ & $10.0(2.0) \mathrm{b}$ & $9.4(1.4) \mathrm{b}$ & $10.1(1.9) \mathrm{b}$ & $8.2(1.9) \mathrm{b}$ \\
WS & $45.7(2.9) \mathrm{a}$ & $38.2(2.3) \mathrm{a}$ & $11.4(1.4) \mathrm{b}$ & $10.3(2.4) \mathrm{b}$ & $8.4(1.5) \mathrm{b}$ & $7.2(1.0) \mathrm{b}$ & $7.2(1.6) \mathrm{b}$ \\
\hline
\end{tabular}

${ }^{\mathrm{z}}$ Standard error of the mean in parentheses. Means with different letters within columns are significantly different according to Tukey's pairwise comparison at $\alpha=0.05$.

Table 2. Effects of water stress on fresh and dry weight, number of runners, and leaf area of the inoculated leaves 3 weeks postinoculation of plants well-watered pre- and postinoculation (WW), water stressed preinoculation and well-watered postinoculation (SW), water stressed pre- and postinoculation (SS), and wellwatered preinoculation and water stressed postinoculation (WS)

\begin{tabular}{lcccc}
\hline Treatment & Fresh weight $(\mathbf{g})$ & Dry weight $(\mathbf{g})$ & Number of runners & Leaf area $\left(\mathbf{m m m}^{2}\right)$ \\
\hline WW & $26.1(1.3) \mathrm{a}^{\mathrm{z}}$ & $4.4(0.2) \mathrm{a}$ & $2.2(0.2) \mathrm{a}$ & $150.7(6.8) \mathrm{a}$ \\
SW & $22.0(1.5) \mathrm{b}$ & $3.9(0.2) \mathrm{a}$ & $1.9(0.3) \mathrm{a}$ & $129.7(7.8) \mathrm{ab}$ \\
SS & $13.0(0.4) \mathrm{c}$ & $2.7(0.1) \mathrm{b}$ & $0.8(0.1) \mathrm{b}$ & $74.8(5.4) \mathrm{c}$ \\
WS & $14.4(0.6) \mathrm{c}$ & $3.2(0.2) \mathrm{b}$ & $0.6(0.2) \mathrm{b}$ & $104.8(6.2) \mathrm{b}$ \\
\hline
\end{tabular}

${ }^{\mathrm{z}}$ Standard error of the mean in parentheses. Means with different letters within columns are significantly different according to Tukey's pairwise comparison at $\alpha=0.05$. 
number of days between the date of inoculation and the date that sporulation was first observed on the inoculated plants. Disease severity was visually recorded as the percentage of the inoculated leaf surface macroscopically colonized by the pathogen at 2 and 3 weeks after inoculation. Aboveground fresh weight, dry weight, number of runners, and leaf area of inoculated leaves were also determined 3 weeks postinoculation.

The percentage of volumetric soil moisture as a function of electric conductivity in the soil of three replicates of three strawberry plants in each treatment group was monitored prior to watering $1,3,7,10$, 12,15 , and 21 days after inoculation using a soil moisture meter (SM150, Delta-T Devices, Cambridge, U.K.).

To assess the viability of the conidial inoculum 21 days after inoculation, five plants (one from each replicate) with powdery mildew colonies from each treatment group were arbitrarily selected. An inoculated leaflet from each plant was gently tapped against a glass microscope slide. The slide was stained with lactofuchsin, and 100 conidia per sample (leaflet) were examined at $400 \times$. Conidia were considered as germinated if they bore a germ tube equal to or longer than the width of the conidium.

Germination of conidia harvested from leaves subjected to water stress. After 2 weeks in quarantine, six powdery mildew-free Korona plug plants were transferred to the greenhouse $\left(16\right.$ to $32^{\circ} \mathrm{C}$, 35 to $95 \% \mathrm{RH}$, and 16-h daylight period). A $15-\mathrm{cm}$-diameter tray was placed beneath each plant, which was potted into an $11-\mathrm{cm}-$ diameter plastic pot containing the growth medium previously described. Three weeks prior to inoculation, the plants were supplied daily with approximately $45 \mathrm{ml}$ of fertilized water as previously specified.

On the day of inoculation, one light green leaf with the leaflets separated and lamina of each leaflet unfolded at an angle of 15 to 30 degrees, and with the leaf blades not yet reflexed from the petiole (i.e., stage 3, Asalf et al. 2014), per plant was tagged. The tagged leaves were inoculated as described previously. Two weeks after inoculation, the plants were divided into two groups, each of which consisted of three plants. The experiment was organized in a randomized block design. One group continued to be watered as described above. Watering ceased completely for the other group. The aim was to obtain a gradient of volumetric soil moisture values ranging from 1 to $50 \%$. The percentage of volumetric soil moisture was monitored for all plants daily using the soil moisture meter previously described.
At $0,24,48,72,96$, and $120 \mathrm{~h}$ after beginning of water stress treatments, conidia from one inoculated leaflet per plant were deposited on the surface of three water agar Petri dishes $(3.5 \mathrm{~cm}$ diameter) by gently touching the diseased leaflet to the agar surface. Petri dishes were sealed and incubated for $24 \mathrm{~h}$ in a growth chamber $\left(18^{\circ} \mathrm{C}, 16\right.$ $\mathrm{h}$ light/8-h dark photoperiod, and $60 \% \mathrm{RH}$ ). A piece of water agar was taken from the center of each Petri dish, mounted on a glass microscope slide, and stained with lactofuchsin, and 100 conidia per sample were examined at $400 \times$ and rated for germination as before. Morphology of conidiophores and conidia was also observed under a light microscope. The experiment was repeated six times.

Statistical analysis. Data of disease severity and germination of $P$. aphanis on the plant were analyzed with analysis of variance (ANOVA) using JMP (SAS Institute, Cary, NC). Additionally, data of soil moisture, fresh weight, dry weight, number of runners, and leaf area of inoculated leaves were analyzed with ANOVA. Data were examined for homogeneity of variance and normality with the Shapiro-Wilk test. Watering condition was considered a fixed effect, and experimental repeat was a random effect. Significant differences among treatment means were determined by Tukey's pairwise comparison at $\alpha=0.05$.

JMP (SAS Institute) was also used to conduct regression analyses on the effect of soil moisture and time on germination of $P$. aphanis. Data were transformed nonlinearly when the residual plot had a nonrandom pattern of data distribution. The transformation method that resulted in the highest coefficient of determination $\left(R^{2}\right)$ is presented.

\section{Results}

Effect of water stress on disease severity in vivo. The soil moisture levels of plants under water stress (SS) was approximately onethird that of plants in the well-watered (WW) treatment. The soil moisture of SW plants rapidly increased as soon as irrigation resumed postinoculation and was equivalent to the WW plants at 3 days postinoculation. The soil moisture of the WS plants decreased more slowly and reached the level of the SS plants on day 7 after inoculation (Table 1). Plant growth was correlated with soil moisture conditions. Water stress either before or after inoculation decreased the fresh and dry weight, number of runners, and area of the inoculated leaf, compared with plants that were well-watered throughout the experiment (Table 2). Furthermore, water-stressed plants developed a
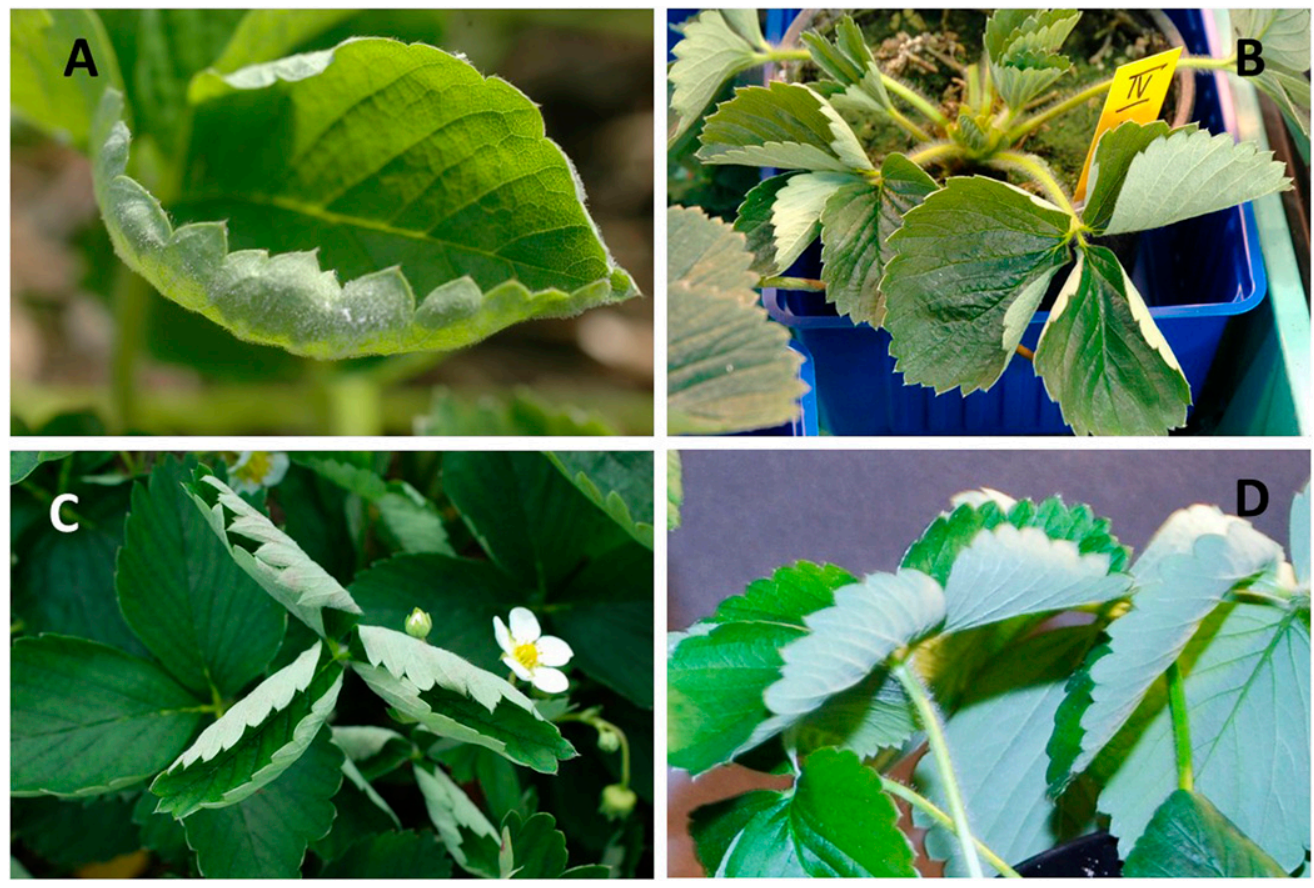

Fig. 1. Well-watered plants infected with powdery mildew (A and $\mathbf{C})$ and water-stressed disease-free plants (B and $\mathbf{D})$, all of strawberry cultivar Korona. 
leaf curling similar to what may be observed in plants infected by powdery mildew (Fig. 1).

The inoculation methods employed yielded a high degree of success. More than $90 \%$ of inoculated leaflets developed mildew symptoms at 14 days postinoculation, and all inoculated leaflets bore mildew colonies 21 days postinoculation, irrespective of pre- or postinoculation water status. The mean disease incidence 9 days postinoculation (standard error of the mean in parentheses) was $60 \%$ (5.26), $62 \%$ (3.29), 64\% (3.23), and 48\% (6.24) for SS, SW, WW, and WS, respectively. Neither the latency period nor the disease incidence values were significantly different among the treatments $(P>0.05)$. Leaf curling symptoms were observed on both noninoculated and inoculated water-stressed plants.

The percentage of the leaf surface colonized by $P$. aphanis was significantly greater on the abaxial compared with the adaxial surface by a factor of about 1.5 at 14 days postinoculation, and by a factor of about 2 by 21 days postinoculation (Fig. $2, P=0.001$ ). At both 14 and 21 days postinoculation, all treatments involving water stress significantly but equivalently reduced disease severity on the abaxial leaf surface. Disease severity on the adaxial leaf surfaces was too low and too variable to detect significant treatment effects at either day 14 or 21 after inoculation (Fig. 2, $P=0.075$ ). Germination of conidia was significantly different among treatments. There was approximately a fourfold reduction in percent germination on SS and WS plants compared with WW and SW plants (Fig. 3, $P=0.001$ ).
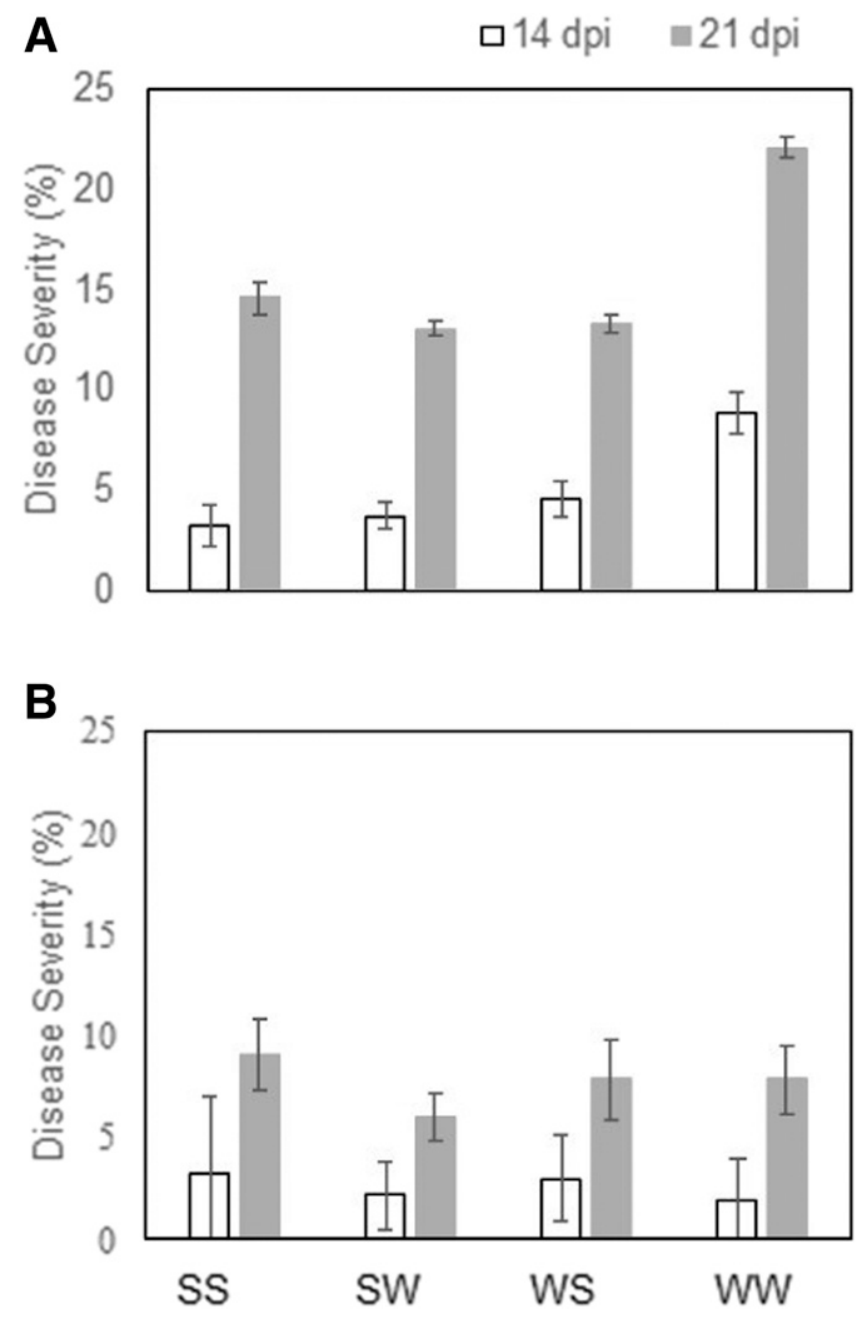

Fig. 2. Disease severity (\%) of Podosphaera aphanis on the abaxial (A) and adaxial (B) leaf side of plants being water stressed pre- and postinoculation (SS), water stressed preinoculation and well-watered postinoculation (SW), well-watered preinoculation and water stressed postinoculation (WS), and well-watered pre- and postinoculation (WW) 14 and 21 days postinoculation (dpi). Vertical bars represent standard error of the mean.
Effect of water stress on germination. Germination of conidia from leaves of strawberry plants was highly correlated with the soil moisture content at the time that the conidia were harvested from plants from 0 to $53 \%$ soil saturation. At the lowest levels of soil moisture, percent conidial germination was near 0 and increased linearly to a maximum of approximately $30 \%$ germination at a soil moisture content of $53 \%$ (Fig. 4, $y=0.54 x+3.02, R^{2}=82.1, P<0.0001$ ), where $y$ is the percent germinated conidia and $x$ is the soil moisture content $(\%)$. We also observed that conidia and conidiophores were shriveled and desiccated on the leaves removed from water-stressed

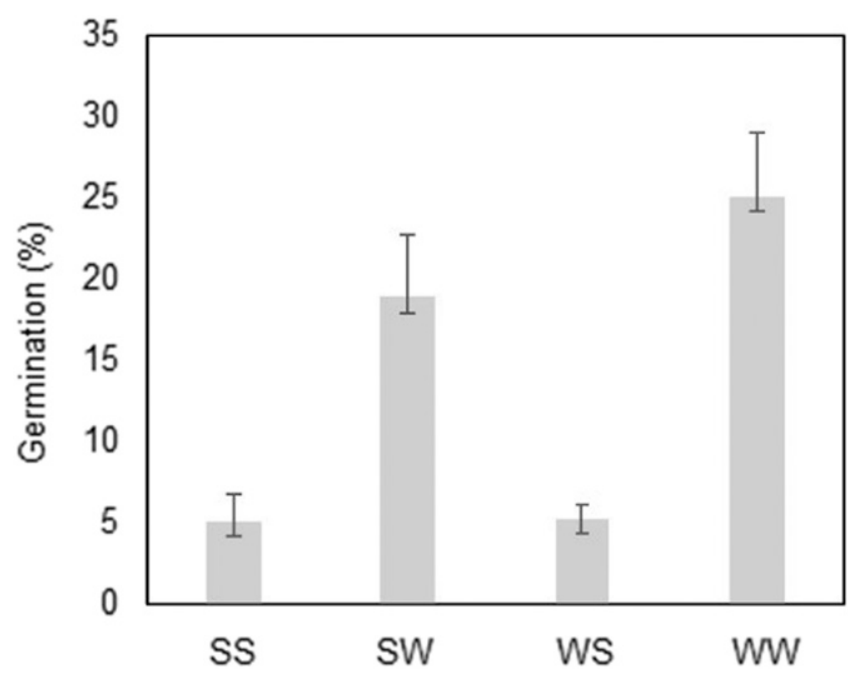

Fig. 3. Germination (\%) 21 days postinoculation of conidia of Podosphaera aphanis from plants being water stressed pre- and postinoculation (SS), water stressed preinoculation and well-watered postinoculation (SW), well-watered preinoculation and water stressed postinoculation (WS), and well-watered pre- and postinoculation (WW). Vertical bars represent standard error of the mean.

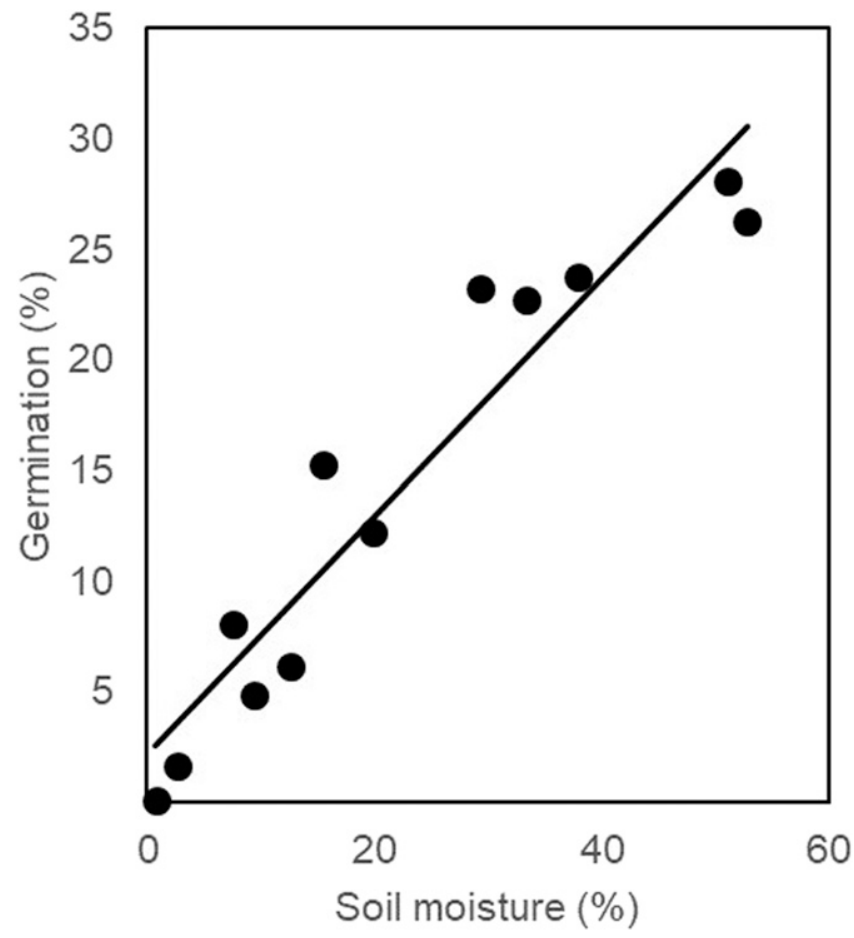

Fig. 4. Effect of soil moisture content on the percentage of conidia that germinated on water agar $24 \mathrm{~h}$ after harvest from leaves of potted strawberry plants $(P<0.0001) ; y=$ percent germinated conidia, and $x=$ soil moisture content $(\%)$. 
compared with well-watered plants $6 \mathrm{~h}$ after the beginning of water stress (Fig. 5).

\section{Discussion}

These experiments clearly indicated that water stress in strawberry suppressed conidial germination and severity of $P$. aphanis. The rate of germination of conidia was proportional to the soil moisture content of the strawberry plants, and water-stressed plants developed less disease than well-watered plants. Our studies relied on soil moisture content to determine the association between water stress and conidial germination. Soil moisture was measured using a soil moisture meter, which is an indirect measure of water stress. Barrs and Weatherley (1962) reported that relative water content, a direct measure, is the most appropriate measure of plant water status. This method, however, is destructive and could not be used for this experiment. Novel, nondestructive direct methodologies, such as thermal imaging or the use of terahertz quantum cascade detectors, could clarify the relationship between water stress and conidial germination and should be considered for future studies (Born et al. 2014; Lee et al. 2019).

Collectively, the foregoing support the commonly observed and reported unfavorability of plant stress in general, and water stress in particular, for a number of powdery mildews (Achuo et al. 2006; Ayres and Woolacott 1980; Caesar and Clerk 1985a; Enright and Cipollini 2011; Moyer et al. 2010; Wiese et al. 2004; Woolacott and Ayres 1984). For example, according to Woolacott and Ayres (1984), mildew-susceptible barley cultivars that experienced water stress exhibited a lower number of colonies, lower rates of colony expansion, lower number of spores per colony, and an increase in the latent period. Additionally, Caesar and Clerk (1985a) reported that the dimensions of conidia and conidiophores of $L$. taurica were reduced by $25 \%$ on water-stressed peppers compared with nonstressed peppers.

The commonly held belief among strawberry growers that severe epidemics of powdery mildew are associated with water stress is difficult to reconcile with the consistently deleterious effects of water stress in the host upon many species within the Erysiphales. However, we believe it is possible that foliar symptoms of leaf curling due to diffuse and inconspicuous infection of the lower leaf surfaces by $P$. aphanis could easily be mistakenly attributed to water stress, which we observed as having a nearly identical leaf-curling symptom in strawberry. Inconspicuous and nonsporulating adaxial leaf infections are common in the early stages of epidemic development in this pathosystem, due to leaf folding and obscuring of the adaxial leaf surface during the ontogenically susceptible stages of leaf emergence

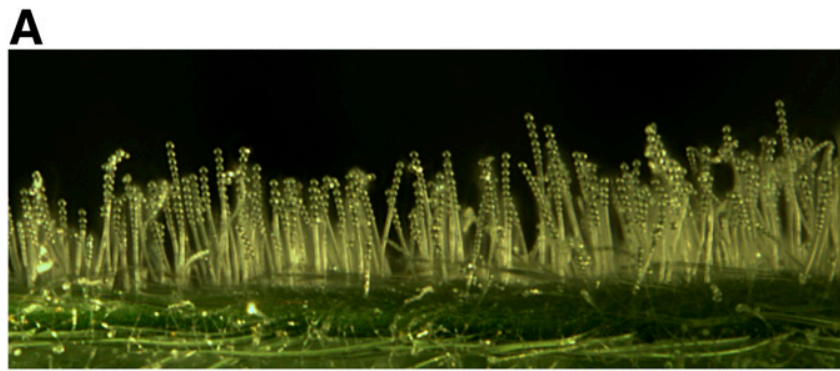

B

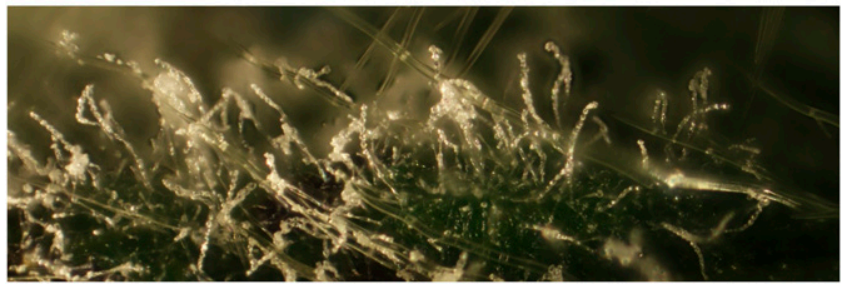

Fig. 5. Conidia and conidiophores on detached leaves from well-watered $(\mathbf{A})$ and water-stressed (B) plants $6 \mathrm{~h}$ after beginning of water stress. and expansion (Asalf et al. 2014). The later sporulation of the abaxial colonies, and the spread to fruit and the adaxial leaf surfaces, would add credence to an association of the symptoms incorrectly attributed to water stress with later conspicuously severe levels of powdery mildew.

Deleterious effects on conidial germination were observed not only at levels of water stress that resulted in visible wilting of plants but also at lower levels of water stress that did not cause wilting. Differential levels of soil moisture across a range generally not associated with wilting (e.g., 20 to $50 \%$ saturation) were well described by a linear model relating the rates of conidial germination to soil moisture content of plants from which the conidia were obtained. Thus, it is possible that germination potential of conidia under field or greenhouse conditions is a dynamic process closely linked to the water relations of the host. Powdery mildews are unique among fungal pathogens in their ability to germinate robustly in the absence of free water. The conidia characteristically bear one or more large water-containing vacuoles that reportedly offset the need for an exogenous water supply. Powdery mildews must absorb water and nutrients from the host plant through the haustoria (Schnathorst 1965; Yarwood 1957). Water stress may make transport of water and nutrients from the host cytoplasm into haustorial cytoplasm more difficult. Further research would be necessary to ascertain if water stress in the host might reduce the quantity of vacuolar water in conidia that develop under water stress in the host.

Perhaps the most significant finding of the present study was not to refute the perception of an association between water stress and more severe development of strawberry powdery mildew. Rather, we quantified the magnitude of the effect of water stress on germination potential of conidia. The magnitude of the impact of mild water stress (e.g., a 50 to $95 \%$ reduction in germination) was equivalent to reported impacts of suboptimal or supraoptimal temperature or RH upon germination in P. aphanis (Amsalem et al. 2006; Caesar and Clerk 1985a; Carroll and Wilcox 2003). However, unlike RH and temperature, host water stress is not presently a component of advisory models for strawberry powdery mildew. Even under conditions of abundant soil moisture, strawberry plants can experience water stress during the warmest parts of the growing seasons in diverse growing regions (e.g., California, Florida, Spain, Italy, Morocco, and Australia). Furthermore, it is possible that the observed effects of host water stress on conidial germination in $P$. aphanis have parallels in other powdery mildew pathosystems. We are continuing studies to incorporate host water status as an additional component to improve accuracy of an advisory system for strawberry powdery mildew and anticipate that similar modifications could be evaluated for advisory models used in other powdery mildew pathosystems.

\section{Literature Cited}

Achuo, E., Prinsen, E., and Höfte, M. 2006. Influence of drought, salt stress and abscisic acid on the resistance of tomato to Botrytis cinerea and Oidium neolycopersici. Plant Pathol. 55:178-186.

Amsalem, L., Freeman, S., Rav-David, D., Nitzani, Y., Sztejnberg, A., Pertot, I., and Elad, Y. 2006. Effect of climatic factors on powdery mildew caused by Sphaerotheca macularis f. sp. fragariae on strawberry. Eur. J. Plant Pathol. 114:283-292.

Asalf, B., Gadoury, D. M., Tronsmo, A. M., Seem, R. C., Dobson, A., Peres, N. A., and Stensvand, A. 2014. Ontogenic resistance of leaves and fruit, and how leaf folding influences the distribution of powdery mildew on strawberry plants colonized by Podosphaera aphanis. Phytopathology 104:954-963.

Austin, C. N., and Wilcox, W. F. 2011. Effects of fruit-zone leaf removal, training systems, and irrigation on the development of grapevine powdery mildew. Am. J. Enol. Vitic. 62:193-198.

Ayres, P., and Woolacott, B. 1980. Effects of soil water level on the development of adult plant resistance to powdery mildew in barley. Ann. Appl. Biol. 94: 255-263.

Barrs, H. D., and Weatherley, P. E. 1962. A re-examination of the relative turgidity techniques for estimating water deficits in leaves. Aust. J. Biol. Sci. 15:413-428

Bencze, S., Balla, K., Bedo, Z., and Veisz, O. 2008. Combined effects of water shortage and fungal diseases on the performance of cereals. Cereal Res. Commun. 36:1099-1102.

Blanco, C., de los Santos, B., Barrau, C., Arroyo, F. T., Porras, M., and Romero, F. 2004. Relationship among concentrations of Sphaerotheca macularis conidia in the air, environmental conditions, and the incidence of powdery mildew in strawberry. Plant Dis. 88:878-881. 
Born, N., Behringer, D., Liepelt, S., Beyer, S., Schwerdtfeger, M., Ziegenhagen, B., and Koch, M. 2014. Monitoring plant drought stress response using terahertz time-domain spectroscopy. Plant Physiol. 164:1571-1577.

Caesar, J. C., and Clerk, G. 1985a. Germinability of Leveillula taurica (powdery mildew) conidia obtained from water-stressed pepper plants. Can. J. Bot. 63: 1681-1684.

Caesar, J. C., and Clerk, G. 1985b. Water stress-induced changes in the morphology of powdery mildew, Leveillula taurica (Lev.). Ann. Phytopathol. 112:217-221.

Carroll, J. E., and Wilcox, W. F. 2003. Effects of humidity on the development of grapevine powdery mildew. Phytopathology 93:1137-1144.

Daubeny, H. A. 1961. Powdery mildew resistance in strawberry progenies. Can. J. Plant Sci. 41:239-243.

Enright, S., and Cipollini, D. 2011. Overlapping defense responses to water limitation and pathogen attack and their consequences for resistance to powdery mildew disease in garlic mustard, Alliaria petiolata. Chemoecology 21:89-98.

Gadoury, D. M., and Pearson, R. C. 1988. Initiation, development, dispersal and survival of cleistothecia of Uncinula necator. Phytopathology 78: 1413-1421.

Jhooty, J. S., and McKeen, W. E. 1965. Studies on powdery mildew of strawberry caused by Sphaerotheca macularis. Phytopathology 55:281-285.

Lee, A., Kim, S., Hong, S., Han, Y., Choi, Y., Kim, M., Yun, S. K., and Kim, G. 2019. Phenotypic analysis of fruit crops water stress using infrared thermal imaging. J. Biosyst. Eng. 44:87-94.
Moyer, M. M., Gadoury, D. M., Cadle-Davidson, L., Dry, I. B., Magarey, P. A., Wilcox, W. F., and Seem, R. C. 2010. Effects of acute low temperature events on development of Erysiphe necator and susceptibility of Vitis vinifera. Phytopathology 100:1240-1249.

Peres, N. A., and Mertely, J. C. 2009. Powdery mildew of strawberries. Publication PP129. Plant Pathology Department, Florida Cooperative Extension Service, Institute of Food and Agricultural Sciences, University of Florida, Gainesville, FL. http://edis.ifas.ufl.edu/pp129.

Peries, O. S. 1962. Studies on strawberry mildew, caused by Sphaerotheca macularis (Wallr. Ex Fries) Jaczewski. 1. Biology of the fungus. Ann. Appl. Biol. 50:211-224.

Schnathorst, W. C. 1965. Environmental relationship in the powdery mildews. Annu. Rev. Phytopathol. 3:343-366.

Strand, L. L. 2008. Integrated Pest Management for Strawberries, 2nd Ed University of California Agriculture and Natural Resources, Oakland, CA.

Weldon, B., Gadoury, D. M., and Cadle-Davidson, L. E. 2017. Cold induced disease resistance may explain unexpected stalling of foliar epidemics of hop powdery mildew (Podosphaera macularis). Phytopathology 107:S5.31.

Wiese, J., Kranz, T., and Schubert, S. 2004. Induction of pathogen resistance in barley by abiotic stress. Plant Biol. 6:529-536.

Woolacott, B., and Ayres, P. G. 1984. Effects of plant age and water stress on production of conidia by Erysiphe graminis f.sp. hordei examined by nondestructive sampling. Trans. Br. Mycol. Soc. 82:449-454.

Yarwood, C. E. 1957. Powdery mildews. Bot. Rev. 23:235-301 